\title{
Hubungan Kontrol Diri dengan Disiplin Siswa Dalam Belajar
}

\author{
Fachrurrozi $_{1}$, Firman $_{2}$, Indra Ibrahim $_{3}$ \\ ${ }^{123}$ Universitas Negeri Padang \\ *Corresponding author, e-mail: firman@konselor.org dan fachrurrozi3194@gmail.com
}

\begin{abstract}
Abstrak
Dewasa ini berbagai permasalahan dialami siswa di sekolah sebagai akibat dari kurang disiplin karena lemahnya kontrol diri mereka. Penelitian ini bertujuan mengungkapkan hubungan kontrol diri dengan disiplin siswa dalam belajar Penelitian ini menggunakan metode kuantitatif dalam bentuk deskriptif korelasional. Populasi penelitian siswa Sekolah Menengah kejuruan Kota padang dengan teknik pengambilan sampel Proportional Random Sampling. Data dikumpulkan melalui angket kontrol diri dan disiplin dalam belajar. Selanjutnya data dianalisis menggunakan statistik deskriptif dan regresi sederhana. Berdasarkan penelitian ditemukan : (1) kontrol diri siswa berada pada kategori sedang, (2) disisiplin belajar siswa berada pada kategi tinggi dan (3) terdapat hubungan antara kontrol diri dengan disiplin siswa dalam belajar.
\end{abstract}

\section{Kata kunci: Disiplin Siswa dalam Belajar, Kontrol Diri.}

\section{Pendahuluan}

Sekolah merupakan salah satu lembaga pendidikan menyiapkan peserta didik untuk mengembangkan potensi yang dimilikinya. Undang-undang Nomor 20 Tahun 2003 pasal 1 ayat 1 tentang Sistem Pendidikan Nasional mengungkapkan pendidikan merupakan usaha sadar serta terencana untuk menciptakan suasana dan proses pembelajaran agar peserta didik aktif mengembangkan potensi diri yang dimemilikinya.

Pengembangkan potensi peserta didik tersebut memerlukan suasana dan proses pembelajaran yang mendukung untuk kegiatan tersebut. Suasana dan proses pembelajaran berjalan dengan lancar bila tercipta kedisiplin siswa dalam belajar. Chaplin (2011: 139) menjelaskan disiplin merupakan kontrol penguasaan diri dengan tujuan menahan impuls yang tidak diinginkan. Di sisi lainAgoes Soejanto (1995: 74) menjelaskan disiplin adalah kunci sukses, sebab dengan disiplin orang menjadi berkeyakinan bahwa disiplin membawa manfaat yang dibuktikan dengan tindakan disiplinnya sendiri. A. Muri Yusuf (1989: 4) menjelaskan kedisiplinan siswa merupakan permasalahan yang harus dengan segera dipecahkan, karena kedisiplinan siswa tersebut merupakan frekuensinya cukup besar menentukan setelah masalah pribadi. Yasin (dalam Hadiyanto, 2013: 59) menjelaskan disiplin adalah kepatuhan terhadap peraturan yang ada atau tunduk pada pengawasan dan pengendalian agar berperilaku tertib dan efisien. Bernhard (dalam Moh. Shochib, 2010: 3) menjelaskan tujuan disiplin meru[pakan upaya pengembangan minat anak dan mengembangkan anak menjadi manusia yang baik, yang akan menjadi sahabat, tetangga, dan warga negara yang baik.

Kedisiplinan sisiwa dalam belajar berumber dari dalam diri sendiri. Syamsul Bachri Thalib (2010: 107) menjelaskan kontrol diri merupakan kemampuan individu untuk mengendalikan dorongan-dorongan, baik dari dalam maupun dari luar diri individu. Mahoney dan Toresan (dalam M Nur Gufron \& Rini Risnawita S, 2010: 22) menjelaskan kontrol diri merupakan jalinan yang secara utuh (integrative) yang dilakukan individu terhadap lingkungannya, individu dengan kontrol diri tinggi sangat memperhatikan cara-cara yang tepat untuk berperilaku dalam situasi yang bervariasi.

Kontrol internal merupakan kontrol diri yang digunakan anak dalam mengarahkan perilakunya, menurutGnagey (dalam Moh. Shochib, 2010: 22). Calhoun dan Acocella (1990: 131) menjelaskan dua alasan yang mengharuskan individu mengontrol diri secara kontinu. Pertama, individu hidup bersama 
kelompok sehingga dalam memuaskan keinginannya individu harus mengontrol perilakunya agar tidak mengganggu kenyamanan orang lain. Kedua, masyarakat mendorong individu untuk secara konstan menyusun standar yang lebih baik baginya. Ketika berusaha memenuhi tuntutan, dibuatkan pengontrolan diri agar dalam proses pencapaian standar tersebut tidak melakukan hal-hal menyimpang.

Berbagai layanan bimbingan dan konseling sudah dilaksanakan di sekolah dalam upaya peningkatan kedisiplinan siswa. Natalia, Firman \& Daharnis (2015) menemukan "information service with using the audio visual media effective to improve students attitude on school discipline" (layanan informasi mempengaruhi pelaksanaan kedisiplinan di sekolah (Natalia, Firman, \& Daharnis, 2015). Selanjutnya layanan informasi mempengaruhi penyesuai diri siswa mematuhi kedisiplinan di sekolah (Indonesia, JDesneli Desneli, Firman Firman, 2016). Kegiatan bimbingan dan konseling sudah berjalan di sekolah, walaupun demikian berdasarkan hasil observasi ditemukan sebagian siswa kurang mematuhi disiplin yang ditunjukan oleh tingkah laku siswa pada bulan septemberditemukan

Bertitik tolak dari uraian tersebut, menarik lebih lanjut untuk dikaji bagaimana hubungan kontrol diri dengan disiplin siswa dalam belajar. Pengungkapan permasalahan ini berguna dalam merumuskan layanan bimbingan dan konseling yang sesuai dengan siswa Sekolah Menengah Kejuruan (SMK).

\section{Metode}

Penelitian ini menggunakan pendekatan kuantitatif dengan jenis deskriptif korelasional. Populasi penelitian Siswa Sekolah Menengah Kejuruan Kota Padang berjumlah sebanyak 219. Pengambilan sampel dilakukan dengan teknik Proportional Random Sampling. Data dikumpulkan dengan kuesioner dengan Skala Likert. Data dianalisis dengan Product Moment Correlation Karl Person.

\section{HASIL DAN PEMBAHASAN}

\section{Hasil Penelitian}

\section{Deskripsi Data Kontrol diri}

Berdasarkan hasil penelitian ditemukan kontrol diri siswa Sekolah Menengah Kejuruan (SMK) Kota Padang dalam belajar, seperti tabel berikut :

Tabel 1. Distribusi Frekuensi dan Persentase Kontrol diri (n=219)

\begin{tabular}{|c|l|c|c|}
\hline Interval Skor & \multicolumn{1}{|c|}{ Kategori } & Frekuensi & \% \\
\hline$\geq 142$ & Sangat Tinggi (ST) & 9 & 4,11 \\
\hline $115-141$ & Tinggi (T) & 93 & 42,5 \\
\hline $88-114$ & Sedang (S) & 101 & 46,1 \\
\hline $61-87$ & Rendah (R) & 16 & 7,31 \\
\hline$<61$ & Sangat Rendah (SR) & 0 & 0 \\
\hline \multicolumn{2}{r}{ Total } & 219 & 100 \\
\hline
\end{tabular}

Berdasarkan Tabel 1 di atas, diperoleh informasi sebagian besar kontrol diri siswa Sekolah Mengah Kejuruan Padang berada pada kategori sedang sebesar 46.1\%, selanjutnya sebesar 42,5\% pada kategori tinggi, 7,31 \% berada pada kategori rendah dan sebesar 4,11\% berada pada kategori sangat tinggi. Dengan demikian dapat disimpulkan sebagian besar siswa SMK Kota Padang memiliki kontrol diri dalam belajar. 
2. Deskripsi Data Disiplin

Berdasarkan hasil penelitian ditemukan disiplin siswa SMK Kota Padang seperti tabel berikut;

Tabel 2. Distribusi Frekuensi dan Persentase Disiplin Siswa

\begin{tabular}{|c|l|c|c|}
\hline Interval Skor & \multicolumn{1}{|c|}{ Kategori } & Frekuensi & \% \\
\hline$\geq 147$ & Sangat Tinggi (ST) & 20 & 9,13 \\
\hline $119-146$ & Tinggi (T) & 177 & 80,8 \\
\hline $91-118$ & Sedang (S) & 22 & 10 \\
\hline $63-90$ & Rendah (R) & 0 & 0 \\
\hline$<63$ & Sangat Rendah (SR) & 0 & 0 \\
\hline \multicolumn{2}{|r|}{ Total } & 219 & 100 \\
\hline
\end{tabular}

Berdasarkan Tabel 2 di atas, Diperoleh informasi sebagian besar siswa SMK Kota Padang memiliki disiplin belajar yang tinggi sebesar $80,8 \%$. Selanjutnya sedang sebesar $10 \%$ dan sangat tinggi $9,13 \%$. Dengan dcemikian dapat disimpulkan sebagian besar siswa SMK Kota padang memiliki disiplin belajar yang tinggi.

3. Hubungan kontrol diri dengan disiplin belajar

Berdasarkan hasil pengujian hipotesis penelitian terlihat pada tabel berikut :

Tabel 3. Hubungan Kontrol Diri dengan Disiplin Siswa

\begin{tabular}{|l|l|r|r|}
\hline \multicolumn{5}{|c|}{ Correlations } \\
\hline \multicolumn{3}{|c|}{} & \multicolumn{1}{|c|}{ D } \\
\hline Pearson Correlation & Disiplin & 1,000 &, 644 \\
\cline { 2 - 4 } & Kontrol Diri &, 644 & 1,000 \\
\hline \multirow{2}{*}{ Sig. (1-tailed) } & Disiplin & &, 000 \\
\cline { 2 - 4 } & Kontrol Diri &, 000 & \\
\hline N & Disiplin & 219 & 219 \\
\cline { 2 - 4 } & Kontrol Diri & 219 & 219 \\
\hline
\end{tabular}

Berdasarkan hasil perhitung menunjukkan koofesien korelasi dari kontrol diri dengan disiplin siswa, yaitu rxy 0,644 dengan $P$ sebesar $0,000(p<0,05)$. Nilai rxy positif menunjukkan arah hubungan kedua variabel positif yang sangat signifikan antara kontrol diri dengan disiplin siswa. Hal ini berarti semakin tinggi kontrol diri, maka semakin tinggi disiplin pada diri siswa, begitu sebaliknya.

Berdasakan hasil pengujian hipotesis di atas, dapat disimpulkan hasil penelitian dalam bentuk gambar hubungan kontrol diri dengan disiplin siswa di SMK Negeri 6 Padang seperti Gambar 2.

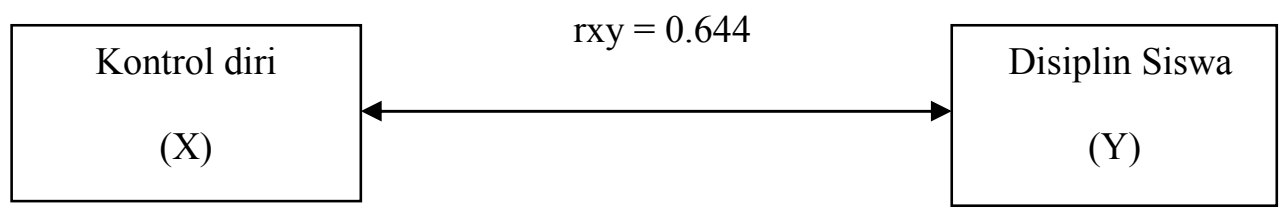

Gambar 2. Hubungan Kontrol diri (X) dengan Disiplin (Y)

\section{Pembahasan}

Berdasarkan hasil penelitian ditemukan sebagian besar siswa SMK Kota Padang memiliki kontrol diri dalam belajar. Kemudian kontrol diri berhubungan positif dan signifikan dengan disiplin siswa dalam belajar, sebesar 0.644. Pada bagian berikut, akan dijelaskan pembahasan variabel yang dikaji dalam penelitian. 


\section{Gambaran Kontrol diri Siswa SMK Negeri 6 Padang}

Hasil analisis data penelitian menunjukkan bahwa secara rata-rata keseluruhan kontrol diri siswa berada dalam kategori sedang. Hal ini berarti kontrol diri siswa masih perlu pengembangan untuk lebih baik dalam meningkatkan disiplin siswa. Berdasarkan pencapaian masing-masing indikator diketahui bahwa tiga indikator termasuk dalam kategori sedang yaitu: 1)kemampuan mengendalikan tingkah laku terhadap tindakan kekerasan, 2)kemampuan mengontrol fikiran terhadap tindakan kekerasan 3)kemampuan memutuskan tindakan sesuai norma dan aturan yang berlaku. Meskipun ditemukan satu indikator dengan kategori tinggi.

Kondisi kontrol diri siswa yang tinggi perlu untuk terus dipertahankan, dikembangkan, dan ditingkatkan dalam meneningkatkan disiplin siswa dalam belajar, demikian juga dengan kondisi kontrol diri siswa yang masih sedang perlu upaya peningkatan. Kontrol diri merupakan salah satu potensi yang dapat dikembangkan oleh setiap individu. Potensi ini dapat digunakan oleh individu selama proses kehidupan, termasuk saat menghadapi kondisi di lingkungan tempat tinggalnya.

Siswa yang memiliki kontrol diri yang tinggi, mereka akan lebih berperilaku yang positif dan mampu bertanggung jawab, seperti tanggung jawab sebagai seorang pelajar adalah belajar (Rianti \& Rahardjo, 2014). Siswa yang mempunyai kontrol diri yang tinggi juga akan mampu memandu, mengarahkan, dan mengatur perilakunya untuk disiplin. Siswa tersebut mampu mengatur stimulus kepada bentuk yang lebih positif sehingga disiplin dalam belajar. Pada penelitian ini capaian tinggi pada indikator kemampuan memutuskan tindakan sesuai norma dan aturan yang berlaku merupakan sebuah proses matangnya kontrol diri siswa dalam mengatasi permasalahan kedisiplinan dalam belajar.

Berdasarkan data penelitian ini, guru BK memegang peranan penting untuk mengembangkan potensi kontrol diri tinggi yang telah dimiliki oleh siswa. Dan juga meningkatkan indikator dari kontrol diri yang masih dalam capaian sedang seperti : kemampuan mengendalikan tingkah laku terhadap tindakan kekerasan dan kemampuan mengontrol fikiran terhadap tindakan kekerasan agar menjadi tinggi dan sangat tinggi. Guru BK perlu terus melatih dan mengembangkan kontrol diri siswa agar tidak menurun, apabila kontrol diri telah menurun maka akan memerlukan proses yang cukup lama untuk meningkatkannya. Oleh sebab itu, guru BK dapat memberikan beberapa layanan BK kepada siswa seperti layanan informasi tentang pentingnya kontrol diri dalam belajar, layanan bimbingan kelompok tentang manfaat kontrol diri dalam keseharian, dan layanan konseling perorangan bagi siswa yang tidak bisa mengontrol diri. Meskipun harus didukung dengan jenis layanan lain yang sesuai dengan tujuan untuk meningkatkan kontrol diri siswa.

\section{Gambaran Disiplin Siswa SMK Negeri 6 Padang}

Berdasarkan hasil penelitian ditemukan sebagian besar siswa SMK Kota padang memiliki disiplin belajar yang tinggi. Disiplin belajar merupakan sesuatu yang urgen dimilki setiap siswa, hal ini sesuai yang dikemukakan oleh Puspitaningtyas (2009) bahwa terciptanya sikap disiplin belajar di sekolah akan mendukung proses kegiatan belajar mengajar yang ada, sehingga siswa akan dapat memperoleh prestasi yang baik. Disiplin belajar siswa yang tinggi perlu dipertahankan melalui berbagai pe;ayanan dalam bimbingan dan konseling misalnya melalui layanan informasi.

\section{Hubungan Kontrol diri dengan Disiplin Siswa}

Berdasarkan hasil penelitian ditemukan hubungan antara kontrol diri dengan disiplin belajar siswa SMK Kota padang. Menurut penjelasan Tu'u, (2004) kontrol diri yang dimiliki siswa berhubungan erat dengan kedisiplinan. Siswa yang memiliki kontrol diri yang tinggi akan mampu menginterprestasikan setiap stimulus yang diberikan, mempertimbangkannya dan memilih tindakan yang akan dilakukan dengan meminimalkan konsekuensi atau dampak yang tidak diinginkan. Sebaliknya, dengan siswa yang memiliki kontrol diri yang rendah, mereka akan kesulitan dalam mengarahkan dan mengatur perilaku sehingga mereka akan cenderung menunda tuntutan tugas sebagai siswa dan mengalihkannya kepada kegiatan yang lebih menyenangkan. Dengan demikian, salah satu cara untuk menghindari ketidakmampuan dalam berdisiplin ialah dengan meningkatkan kontrol diri yang terdapat pada diri siswa.

Hasil penelitian, di perkuat oleh teori Thompson (dalam Smet 1994) menjelaskan bahwa seseorang merasa memiliki kontrol diri ketika mereka mampu mengenal apa yang dapat dan tidak dapat dipengaruhi lewat tindakan pribadi dalam suatu situasi, ketika mereka memfokuskan pada bagian yang 
dapat dikontrol lewat tindakan pribadi. Selanjutnya, Hurlock (2004) menjelaskan bahwa individu yang memiliki kontrol diri memiliki kesiapan diri untuk berperilaku sesuai dengan tuntutan norma, adat, nilainilai yang bersumber dari ajaran agama dan tuntutan lingkungan masyarakat dimana individu tinggal. Kontrol diri merupakan suatu potensi yang dapat dikembangkan dan digunakan individu selama prosesproses dalam kehidupan, termasuk dalam menghadapi kondisi yang terdapat di lingkungan sekitarnya.

Secara umum orang yang mempunyai kontrol diri yang tinggi akan mengarahkan dirinya pada perilaku yang positif. Seorang siswa yang mempunyai kontrol diri yang tinggi sangat memperhatikan cara yang tepat untuk berperilaku dalam situasional, bertanggung jawab sesuai dengan tata tertib yang ada. Sebaliknya siswa yang mempunyai kontrol diri yang rendah cenderung perilakunya menyimpang dari aturan-aturan yang ada. Sehingga dapat dikatakan siswa yang memiliki kontrol diri yang rendah akan berperilaku dan bertindak kepada hal-hal yang lebih menyenangkan dirinya meskipun tidak mematuhi aturan yang berlaku disekolah. Berdasarkan penjelasan di atas, dapat dipahami bahwa begitu pentingnya kontrol diri untuk mengurangi disiplin. Salah satu yang harus ditingkatkan dan dikembangkan pada setiap individu adalah kontrol diri.

\section{DAFTAR RUJUKAN}

A. Muri Yusuf. 1987. Statistik Pendidikan. Padang: Angkasa Raya.

A. Muri Yusuf. 2007. Metodologi Penelitian. Padang: UNP Press.

Alex Sobur. 1991. Anak Masa Depan. Bandung: Angkasa

Agus Soejanto. 1995. Bimbingan Ke Arah Belajar yang Sukses. Jakarta: Angkasa Baru.

Anas Sudijono. 2011. Pengantar Statistik Pendidikan. Jakarta: Raja Grafindo.

Ali Imron. 2012. Manajemen Peserta Didik Berbasis Sekolah. Jakarta: Bumi Aksara.

Bernadus Widodo. 2013. Perilaku Disiplin Siswa Ditinjau Dari Aspek Pengendalian Diri (Selft Control) Dan KeterbukaanDiri(Self Disclosure) Pada Siswa SMK Wonorasi Caruban Kabupaten Mediun. Jurnal Widya Warta No. 01 Tahun XXXV II/ Januari.140-151.

Calhun. J. F dan Acocella. J. R. 1990. Psikologi tentang Penyesuaian dan Hubugan Kemanusiaan. (Terjemah RS. Satmoko). Semarang: IKIP Semarang Press.

Hurlock, Elizabeth B. 1980. Psikologi Perkembangan: suatu pendekatan sepanjang rentang kehidupan. Jakarta: Erlangga.

Hurlock, Elizabeth B. 1978. Perkembangan Anak. Jakarta: Erlangga.

Febriche Amriani. 2011. Pelanggaran Disiplin yang Dilakukan Siswa Di Sekolah(Studi deskriptif terhadap siswa SMP N 15 Padang). Skripsi tidak diterbitkan. Padang: BK FIP UNP.

Hadiyanto. 2013. Manajemen Peserta Didik Bernuasa Pendidikan Karakter. Padang: UNP Press.

Instruksi Mentri Pendidikan dan Kebudayaan No 14/U/1979 tertanggal 1 Mei 1974. Jakarta: Mendikbud

Indonesia, JDesneli Desneli, Firman Firman, A. S. P. (2016). Layanan Informasi. Jurnal EDUCATIO: Jurnal Pendidikan Indonesia, 2, 9-13.

J. P Chaplin. 2011. Kamus Lengkap Pisikologi. (Terjemah Kartini Kartono). Jakarta: Rajawali Press.

M Nur Gufron \& Rini Risnawati . 2010. Teori Psikologi. Jakarta: Ar-Ruzz Media

Moh Shoehib. 2010. Pola Asuh Orang Tua Dalam Membantu AnakMengembangka Disiplin Diri. Jakarta: Rineka Cipta. 
Natalia, N., Firman, \& Daharnis. (2015). Efektivitas Layanan Informasi dengan Menggunakan Media Audio Visual dalam Meningkatkan Sikap Siswa terhadap Kedisiplinan Sekolah. Jurnal Konseling Dan Pendidikan ISSN Cetak: 2337-6740 - ISSN Online: 2337-6880 Http://jurnal.konselingindonesia.com Volume 3 Nomor 2, Juni 2015, Hlm 40-48 Info, 40-48.

Oemar Hamalik. 2004. Psikologi Belajar Megajar. Bandug: Sinar Baru Algesindo.

Risa Nur Aisyah. 2012. Huungan Antara Perhatian Orangtua Dengan Disiplin Anak Di Sekolah. Skripsi tidak diteritkan. Padang: BK FIP UNP.

Sofan Amri. 2013. Pengembanga \& Model Pemelajaran dalam Kurikulum 2013. Jakarta: Prestasi Pustakaraya.

Sugiyono. 2009. Metode Penelitian Pendidikan. Bandung: Alfabeta

Suharsimi Arikunto. 2002. Metode Penelitian. Jakarta: Rineka Cipta.

Soejitno Irmin dan Abdul Rochim. 2004. Membangun Disiplin Diri Melalui Kecerdasan Spritual dan Emosional. Jakarta: Batavia Press.

Syamsul Bahri Thalib. 2010. Psikologi Pendidikan Berbasis Analisis Empiris Aplikatif. Jakarta: Kencana.

Syaiful Bahri Djamarah. 2008. Rahasia Sukses Belajar. Jakarta: Rineka Cipta

The Liang Gie. 1995. Cara Belajar yang Efisien. Yogyakarta: Liberty.

Tulus Tu'u. 2004. Peran Disiplin Pada Perilaku dan Prestasi Siswa. Jakarta: Grasindo.

Undang-undang Nomor 20 Tahun 2003 pasal 1 ayat 1 tentang Sistem Pendidikan Nasional. 2013. Jakarta: Karya Gemilang. 2001. 